\title{
The Development of Recency and Frequency Memory: Is There a Developmental Shift from Reliance on Trace-Strength to Episodic Recall?
}

\author{
Teresa McCormack and James Russell
}

University of Cambridge, Cambridge, United Kingdom

\begin{abstract}
Recency and frequency judgements can be made either on the basis of the familiarity of items or by retrieving item-specific contextual information. Although normal adults seem to use the latter basis, several studies have shown that adults with memory impairments rely on trace-strength information. We report the results of a study examining the basis of 4-, 6-, and 8-year-old children's recency and frequency judgements. Both the frequency and the recency of presentation of items were manipulated such that reliance on trace-strength would lead to a characteristic pattern of performance, as shown by amnesic patients. Although the accuracy of both recency and frequency judgements improved between 4 and 6 years of age, there was no evidence that children in any age-group based their recency judgements on trace-strength, although there was some indication that 4-year-olds may have used this basis for judgements of frequency. (c) 1997 Academic Press
\end{abstract}

Memory theorists have often distinguished between essentially automatic, familiarity-based memory processes or systems and more effortful, conscious recall of a specific event, episode, or item occurrence. Although the descriptions of these two types of systems or processes vary considerably (e.g., Jacoby, 1991; Roediger, 1990; Schacter, 1987; Tulving, 1983, 1985), these kinds of distinctions have proved useful in considering the intact and impaired memory processes in amnesia (e.g., Cermack, Verfaellie, \& Sweeney, 1992; Verfaellie, Bauer, \& Bowers, 1991) and, more recently, in characterizing which kinds of memory processes may be innate and which emerge gradually with development (e.g., Naito \& Komatsu, 1993; Parkin \& Streete, 1988; Schacter \& Moscovitch, 1984).

We are grateful to Chris Jarrold, William Friedman, and an anonymous reviewer for their comments on an earlier draft of this paper.

Address correspondence and reprint requests to Teresa McCormack, who is now at the Department of Psychology, University of Warwick, Coventry, CV4 7AL, E-mail: T.M.McCormack@ warwick.ac.uk. 
A number of neuropsychological studies have demonstrated an important qualitative difference between the memory judgements of amnesic patients and those of normal adults. For example, Verfaillie and Treadwell (1993) have shown that amnesic subjects tend to base their recognition judgements on familiarity rather than on episodic recall, a tendency we have also reported in 4-year-olds (McCormack \& Russell, 1995). Similarly, amnesic patients seem to base judgements of recency and frequency of occurrence on the familiarity of items, whereas normal adults base such judgements on some kind of item-specific contextual information (Huppert \& Piercy, 1978; Mayes, Baddeley, Cockburn, Pickering, \& Wilson, 1989; Meudell, Mayes, Ostergaard, \& Pickering, 1985). This difference is consistent with the view that amnesia is characterized by difficulties remembering episodic information, such as temporal context, although more automatic, familiarity-based memory processes may be intact (see Mayes, Meudell, \& Pickering, 1985).

In a recent review of theories of memory for temporal information, Friedman (1993) made a relevant distinction between "distance-based" theories and "location-based" theories, which provide quite different descriptions of the cognitive processes involved in making temporal judgements. The former type of theory describes temporal memory as depending upon forgetting processes which are correlated in some way with the passage of time. Most commonly, the "strength of trace" or familiarity of an item or event is thought to decline over time. Therefore, strength-theories describe the function which relates strength and time and the decision rules used to translate measures of strength into responses (e.g., Hinrichs, 1970; Wickelgren \& Norman, 1966). In contrast, location-based theories describe the encoding and retrieval of item-specific contextual information upon which temporal judgements are based. Such information could be the output of a time-tagging mechanism (e.g., Hasher \& Zacks, 1979) or could be other associated contextual information which can be used inferentially to make temporal memory judgements (Block, 1982; Friedman \& Wilkins, 1985; Guenther \& Linton, 1975; Hintzman, Block, \& Summers, 1973; Tzeng, Lee, \& Wetzel, 1979). For example, Hintzman et al. (1973) suggested that information about internal mood states such as boredom, external cues such as instructions to begin study, and associations to other items could all have temporal meaning.

Although studies with normal adults have provided considerably stronger support for location-based theories than for distance-based accounts, the finding that amnesic patients seem to rely on trace-strength to make judgements of temporal recency is a robust one (Huppert \& Piercy, 1978; Mayes et al., 1989; Meudell et al., 1985). If trace-strength is not a particularly accurate basis for temporal judgements under most circumstances, this reliance can also explain the temporal memory impairments of such patients (e.g., Parkin, Leng, \& Hunkin, 1990; Shaw \& Aggleton, 1995; Shimamura, Janowsky, \& Squire, 1991; Squire, 1982). Recent lifespan research has indicated that a tendency to base temporal judgements on trace-strength is not restricted to 
clinical populations: the decline in memory for temporal information associated with aging has also been described in terms of a shift to use of automatic, familiarity-based processing (Bartlett, Strater, \& Fulton, 1991; Parkin \& Walter, 1992).

Friedman (1992a) has argued that young children may also base their recency judgements on a distance-based process such as trace-strength, although for different reasons. He suggested that children's well-documented problems understanding conventional time-frames (e.g., Friedman, 1978, 1989), such as the clock and calendar system, will lead to a reliance on more impressionistic distance-based processes. Friedman, Gardiner, and Zubin (1995) showed that, although even 4-year-old children were better than chance at judging the relative recency of their birthday and Christmas, these judgements could not have been based on an understanding of the positions of these events within the calendar year. In fact, children's accuracy was best predicted by the ratio of the distances of the two events in the past, as a trace-strength theory might predict.

As Friedman has pointed out, children's lack of understanding of conventional time systems deprives them of a rich source of temporal information, and his studies have shown that 4-year-olds can neither remember calendar dates nor use other contextual information to infer such information (Friedman, 1991). In addition, regardless of the level of understanding of time systems, several studies have shown that there are some developmental changes in the ability to either recall or use episodic, contextual information (e.g., Brown, 1973a; Brown, Campione, \& Gilliard, 1974; Rybash \& Colilla, 1994). Indeed, some theorists have argued that familiarity-based memory processes are present early in development, if not from birth, whereas memory systems or processes responsible for episodic recall develop gradually (e.g., Naito \& Komatsu, 1993; Schacter \& Moscovitch, 1984). Although this claim is plausible, disputes over what counts as episodic recall make it difficult to investigate the basis of memory judgements experimentally.

The aim of the current study was to investigate whether young children can base their memory judgements on episodic item-specific contextual information or whether there is a developmental shift from reliance on tracestrength to retrieval of such information. We adapted a neuropsychological paradigm which has been previously used to examine such a shift following brain injury. In this paradigm, the trace-strength of items is manipulated by varying their frequency of presentation, with items presented one or three times, a manipulation which ensures that the trace-strength of items is not proportional to recency of presentation. Therefore, subjects basing their recency judgements on trace-strength alone will make systematic errors. Recency of presentation is manipulated by showing two lists on consecutive days, a manipulation which ensures that trace-strength is not proportional to frequency of presentation, leading to errors if subjects are basing their frequency judgements on trace-strength alone. 
In the subsequent tests of recency and frequency, particular patterns of responding are predicted if subjects are relying on trace-strength: first, recency judgements should be affected by the frequency of presentation such that repeated items are judged as having occurred more recently; and second, frequency judgements should be affected by the recency of presentation such that more recent items should be judged as having occurred more frequently. Studies have consistently found a tendency for amnesic subjects to give "today" judgements for items seen three times on the first day (Huppert \& Piercy, 1978; Mayes et al., 1989; Meudell et al., 1985). These studies have also shown that the recency of items affects frequency judgements - amnesic patients tend to give "one time" answers for items seen the previous day, and "three times" answers for items seen that day. In other words, there is a distinctive pattern to their errors which suggests a reliance on trace-strength. Normal adult subjects show no such pattern in their errors, although Bartlett et al. (1991) have reported a similar pattern in a study of elderly adults' recency discrimination of faces.

The current study adapted this neuropsychological paradigm to examine whether young children also show the distinctive pattern of performance which indicates a reliance on trace-strength. Since the recency judgements involved children making a choice between whether an item was presented "yesterday" or "today," 4-year-olds were the youngest age-group to participate in the study. Previous studies have shown that an understanding of yesterday-today distinction occurs in the third year (see Friedman, 1978). For example, Harner (1975) found that although 4-year-olds occasionally confused "yesterday" and "tomorrow," by 3 years, children at least understand that "yesterday" refers to "a time other than today." This was the only understanding of conventional time systems relevant to the task, due to the short 24-h time-period involved. Therefore, if children do rely on tracestrength, it would be due to problems retrieving or using item-specific contextual information, problems which we predicted would lead to a developmental shift from reliance on trace-strength to retrieving such information. More specifically, we predicted that the youngest children may show the lack of differentiation of recency and frequency of items which indicates reliance on trace-strength, whereas older children's performance may resemble that of normal adults, indicating recall of episodic information.

On the basis of previous findings (Friedman, 1992b, 1991), it was expected that even the youngest children would perform at a level better than chance on the recency task, as do amnesic patients. Indeed, Huppert and Piercy originally suggested that familiarity-based memory processes are preserved in order to account for amnesics' surprising ability to perform at a level above chance on their memory test. However, if there is a developmental shift from reliance on trace-strength to retrieval of contextual information, there should be improvements in accuracy with age.

Theories of frequency memory are analogous to those for temporal informa- 
tion in that they can be considered to be based on trace-strength of items or on the retrieval of some information specifically about the frequency of items. Hasher and Zacks (1979) have suggested that frequency judgements normally involve the retrieval of frequency information which is encoded automatically by a specialized memory mechanism, a view which receives some support by the lack of developmental improvements found in several studies (Connolly, Hockley, \& Pratt, 1996; Hasher \& Zacks, 1979). Although a number of other studies have reported developmental differences, for the most part such differences have been between 5-year-olds and children aged from 6 to 8 years (Ellis, Palmer, \& Reeves, 1988; Ghatala \& Levin, 1973; Lund, Hall, Wilson, \& Humphreys, 1983). For example, Ellis et al. (1988) found that 6year-olds were more accurate than 5-year-olds at judging the frequency of pictorial stimuli, but there were no further developmental improvements between 6 and 11 years. Ellis et al. argued that the poorer performance of 5year-olds may actually be due to unfamiliarity with the stimuli or to attentional factors. Alternatively, perhaps memory for event frequency matures in the first few years and subsequently remains invariant. One possible explanation for development improvements, such as those found by Ellis et al. (1988), may be a shift from judging frequency on the basis of trace-strength to retrieval of information specifically about event frequency. The current study addresses this possibility by examining whether the frequency judgements of 4-year-olds show a lack of differentiation of recency and frequency of items.

\section{METHOD}

\section{Subjects}

The subjects were 54 children drawn from primary and nursery schools in Cambridgeshire, UK. Children were predominately of Caucasian origin and of lower-middle social class. There were 18 children in each of three different age groups: 4 years $(M=4.6$ yrs, 11 girls and 7 boys $), 6$ years $(M=6.5$ yrs, 8 girls and 10 boys), and 8 years $(M=8.3$ yrs, 6 girls and 12 boys).

\section{Materials}

The stimuli consisted of 72 colored line drawings of common objects printed on cards and divided into two sets. They were chosen to be objects familiar to children in the youngest age group. The first set, for use on Day 1 , consisted of 36 different pictures, 18 of which were presented once and 18 of which were presented 3 times, making a total of 72 cards in the set. The order of pictures in the set was random, with the exception that repeated pictures were separated by an interval of at least 5 other cards. The second set, for use on Day 2, was made up in an identical way, using 72 cards, and 36 different pictures. The test stimuli were 2 sets of pictures, each composed of 36 items from the 2 previous lists: 9 Day 1 Frequency 1 items, 9 Day 1 Frequency 3 items, 9 Day 2 Frequency 1 items, and 9 Day 2 Frequency 3 
items. One of these sets was used for the frequency test and one for the recency test. (Due to a procedural oversight, which set of items was used as the Day 1 set and which was used as the Day 2 set was not counterbalanced across subjects.)

\section{Procedure}

The procedure resembled closely that of the relevant neuropsychological studies (Huppert \& Piercy, 1978; Mayes et al., 1989; Meudell et al, 1985), in terms of the length of the delay between presentation of the two lists and the delay between presentation of the second list and test. The only significant methodological changes were the reduction in the number of stimuli used (approximately half), and the counterbalancing of the order of frequency and recency tests (the recency test had always been administered first in the neuropsychological studies).

Each child was seen individually in a quiet corner of the classroom or a nearby room. Children were told that the experimenter had come to study how well the children in the class remembered things. On the first day, the experimenter explained that they were going to look at some pictures together and that she would return tomorrow to see children again to ask them some questions about the pictures they had seen. Children were told to look at each picture carefully and to try to remember it. They were also told that some of the pictures would be seen once and some three times. The children were then shown the Day 1 items and asked to name each picture as it was presented, with exposure time being around $3 \mathrm{~s}$ for each card. Children were encouraged to name the pictures to ensure that they paid attention to the whole set of 72 items. After presentation of this set, children were told again that the experimenter would return the following day and that they would be asked some questions about the pictures.

The children were then seen $24 \mathrm{~h}$ later by the same experimenter. They were prompted with: "Do you remember that I came in yesterday and we looked at some pictures together?' and then told that today they would see some more pictures. It was explained to them that they would subsequently be asked some questions about all the pictures they had seen with the experimenter. The children were given the same instructions for Day 2 items as for Day 1, and then the Day 2 set was shown to then in an identical manner. After presentation of the Day 2 items, children were reminded that they would be asked to come back in 10 minutes to answer some questions about all the pictures - "today's and yesterday's" - that they had seen. Children then returned to their classroom activities. After a 10-minute break, children were tested on a recency and a frequency test. The order in which children received the tests was counterbalanced, with half the children receiving the recency test first and half the frequency test first.

For the recency test, children were reminded that they had seen two sets of pictures - "Do you remember we saw some pictures today together and 
we saw some different pictures yesterday, the last time I came in ?' They were then told that they would be shown some of those pictures and would be asked to say for each picture whether they saw it today or yesterday. Children were then shown the first item in the test set, and asked "Did you see this picture today with me or did you see it yesterday?" This question was repeated for subsequent items if the child appeared to need this kind of prompt (which the majority of children did not). If the child gave any answer other than today or yesterday, then the question was repeated for that item. For the frequency test, children were reminded that they had seen some of the pictures one time and some three times. Children were then told that they would be shown some of the pictures they had seen with the experimenter and would be asked to say for each picture whether they saw it one time or three times. Children were then shown the first test item and asked "Did you see this picture one time or did you see it three times?" As with the recency test, this question was repeated for subsequent items if the child needed the prompt or if she or he gave an answer other than one or three.

\section{RESULTS}

Since the tests used were forced-choice, it was necessary to transform the raw data to control for response biases. Following the analysis used in previous similar studies, the number of erroneous responses made to each type of item was divided by the number of times that response was given in total (for each subject). For example, the number of erroneous "today" responses given to Day 1 Frequency 3 items was divided by the total number of "today", responses given by that subject during the recency test, giving the proportion of all "today" responses given to Day 1 Frequency 3 items. The analyses of these proportions reported below were all carried out on untransformed data, since the pattern of results after arcsin transformation of the data was identical (analysis of the raw data rather than proportional data also gives a very similar pattern of results).

\section{Recency Judgements}

Table 1 shows the mean number of error responses made for each type of item as a proportion of all responses of that type. To interpret the results, it is necessary to distinguish between the pattern of responses predicted by a trace-strength account of recency judgements and the pattern predicted if subjects were using contextual information. For items presented on the first day, reliance on trace-strength would lead to more erroneous "today" responses to Frequency 3 items than Frequency 1 items, since these would seem more familiar. However, for items presented on the second day, more erroneous "yesterday" responses would be expected for Frequency 1 items than Frequency 3 items since these would feel less familiar. If subjects were using contextual information, they would be expected to be more accurate on repeated items on both days since repetition presumably provides more 
TABLE 1

Proportions of Responses which are Erroneous in the Recency and Frequency Tasks

Type of Test Item

\begin{tabular}{|c|c|c|c|c|c|c|c|c|}
\hline \multirow[b]{2}{*}{ Age group } & \multicolumn{2}{|c|}{ Day 1 Freq. 1} & \multicolumn{2}{|c|}{ Day 1 Freq. 3} & \multicolumn{2}{|c|}{ Day 2 Freq. 1} & \multicolumn{2}{|c|}{ Day 3 Freq. 3} \\
\hline & $M$ & $S D$ & $M$ & $S D$ & $M$ & $S D$ & $M$ & $S D$ \\
\hline \multicolumn{9}{|c|}{ Recency test } \\
\hline 4 years & 0.15 & 0.09 & 0.08 & 0.08 & 0.11 & 0.09 & 0.13 & 0.08 \\
\hline 6 years & 0.06 & 0.08 & 0.03 & 0.04 & 0.08 & 0.05 & 0.03 & 0.04 \\
\hline 8 years & 0.06 & 0.07 & 0.01 & 0.03 & 0.11 & 0.08 & 0.05 & 0.04 \\
\hline \multicolumn{9}{|c|}{ Frequency test } \\
\hline 4 years & 0.15 & 0.11 & 0.23 & 0.11 & 0.19 & 0.11 & 0.12 & 0.12 \\
\hline 6 years & 0.15 & 0.09 & 0.15 & 0.08 & 0.11 & 0.08 & 0.08 & 0.09 \\
\hline 8 years & 0.13 & 0.09 & 0.13 & 0.09 & 0.09 & 0.06 & 0.07 & 0.06 \\
\hline
\end{tabular}

of the relevant information. Therefore, a reliance on trace-strength would be expected to yield an interaction between the effects of recency of presentation and frequency of presentation, whereas use of contextual information would be expected to yield a consistent effect of frequency of presentation.

It can be seen from Table 1 that the proportions of responses which were erroneous were typically quite small, particularly for repeated items, and that 6- and 8-year-olds performed better than the 4-year-olds. The error scores were subjected to an analysis of variance (ANOVA), with between-subjects factors of Age (3 levels, 4, 6, and 8 years) and Order of test (since half the children received the recency test first and half the frequency test first, this factor had 2 levels), and within-subjects factors of Day (2 levels, Day 1 and Day 2) and Frequency (2 levels, Frequency 1 and Frequency 3). The results showed a significant main effect of Age $[F(2,48)=11.04, p<.01]$. A Newman-Keuls pairwise comparison revealed that this was due to the performance of the 4-year-olds being significantly worse $(p<.01)$ than that of the 6- and the 8-year-olds. There was no significant difference between the two older groups. There was no significant effect of Order $[F(1,48)=0.16, p=.69]$. There were, however, significant main effects of Day $[F(1,48)=5.48, p<.05]$ and Frequency $[F(1,48)=34.18, p<.01]$. Performance on Day 1 items was better overall than performance on Day 2 items and performance on Frequency 3 items was better than Frequency 1 items. There was no significant Day by Frequency interaction $[F(1,48)=1.57, p=.22]$. However, there was a significant Age by Day by Frequency interaction $[F(2,48)=4.03, p<.05]$.

If children use trace-strength as a basis for their responses, a Day by Frequency interaction is predicted, since there would be more errors made to 
Frequency 3 items from Day 1 but more errors made to Frequency 1 items from Day 2. If there is a developmental shift in the basis of recency judgements from familiarity to contextual retrieval, then a 3-way interaction between Age, Day, and Frequency is predicted.

Since such an interaction had been found, it was examined at each level of the variables to discover if it was in the predicted direction. It was found that the only group for which there was a significant Day by Frequency interaction was the 4-year-olds $[F(1,51)=9.0, p<.01]$. Post-hoc analysis of simple effects showed there to be an effect of Day at Frequency 3 only $[F(1,17)=11.77, p<.01]$ and an effect of Frequency at Day 1 only $[F(1,17)=19.32, p<0.01]$. Inspection of the means reveals that fewer errors were made on Day 1 Frequency 3 items than on any other item type, and that the advantage of the repetition of items was restricted to Day 1 items for the 4-year-olds. Additionally, an Age by Frequency interaction was found for Day 2 items only $[F(1,51)=3.43, p<.05]$. Post-hoc analysis of simple effects revealed an effect of Age on Frequency 3 items but not Frequency 1 items $[F(2,51)=11.62, p<.01]$, and an effect of Frequency for the older groups of children only $[F(1,51)=0.47, p=.50$ for the 4-year-olds, but $F(1,51)=6.00, p<.01$ for the 6 -year-olds, and $F(1,51)=6.77, p<.01$ for the 8 -year-olds].

Therefore, the three-way interaction is due to the differential effects of repeating items over the two days on the performance of the younger children. The 4-year-olds did particularly well on Day 1 Frequency 3 items and showed an advantage on Frequency 3 items over Frequency 1 on Day 1. However, they were the only group not to do better on Frequency 3 than Frequency 1 items from the second day. Their level of performance was not significantly different from the older children on Day 2 Frequency 1 items, but they failed to show the benefit of repeated presentation on Day 2 items. The left-hand panel of Fig. 1 illustrates this interaction between Day and Frequency found for the 4-year-olds and can be compared with the right-hand panel of Fig. 1, which shows the performance of the 6- and 8-year-olds combined, who show a consistent benefit for repeated items.

This interaction is, in fact, the reverse of the interaction which would have indicated that the younger children were relying on trace-strength: if this had been the case, the 4-year-olds would have been better on Day 1 Frequency 1 than Day 1 Frequency 3 items (like the older children, they were, in fact, significantly worse); and they would be more accurate on Day 2 Frequency 3 than Day 2 Frequency 1 items (they were the only group which did not show this increased accuracy and, in fact, there was a nonsignificant tendency for them to be more accurate on Day 2 Frequency 1 items than on Day 2 Frequency 3 items). Thus, the predicted interaction for Day and Frequency was not found, and therefore there is no support for the hypothesis that the younger children are more reliant on trace-strength.

The finding that the youngest children make many errors on Day 2 Fre- 
4-year-olds

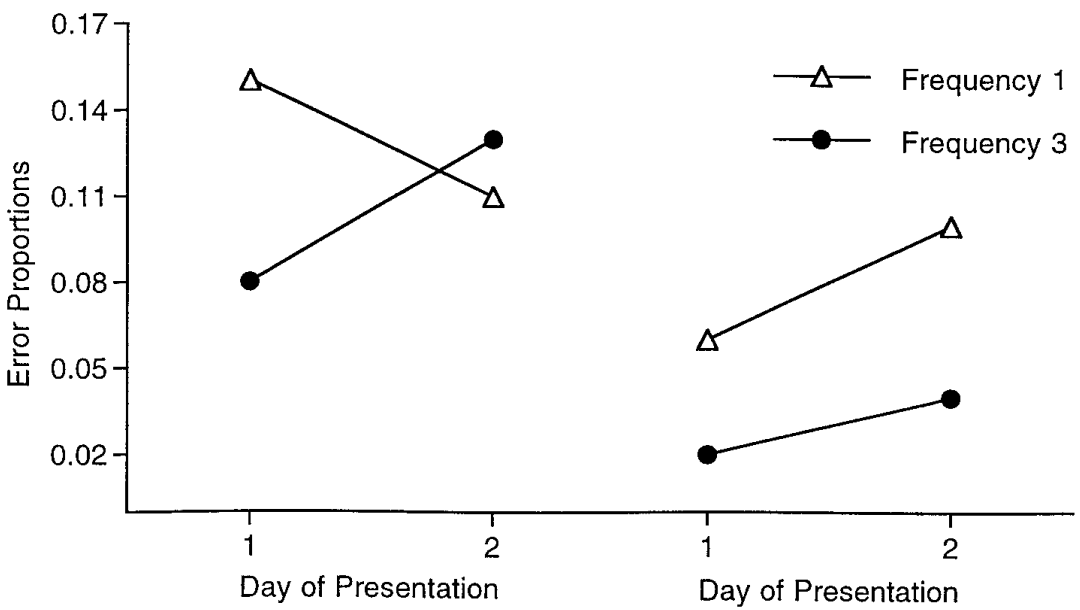

FIG. 1. Mean proportions of recency responses that are errors for 4-year-olds and for 6- and 8-year-olds combined.

quency 3 items is a puzzling one. As mentioned above, both a familiarity account and a contextual account of recency judgements predict better performance on Day 2 Frequency 3 items than on Day 2 Frequency 1 items. The weaker trace-strength of Frequency 1 items may lead to them being mistakenly judged as occurring the day before and, on a contextual account, repeated presentation would give more specific information about time of occurrence. Therefore, younger children's performance is different from that of older children, adults, and amnesic patients (see Meudell et al., 1985).

To summarize, the results do show that there is an age-related improvement in ability to make recency judgements, although there was no difference between the two older groups. In the older children, judgements tended to be more accurate for Day 1 items than for Day 2 items, a tendency which is also evident in the Meudell et al. (1985) data. Repetition of items tended to improve the ability of children to place those items in a temporal context. Therefore, there is no support for the suggestion that the basis of such judgements shifts developmentally from trace-strength to retrieval of context. However, it is unclear why the youngest children found Day 2 Frequency 3 items so difficult.

\section{Frequency Judgements}

Table 1 shows the mean number of error responses made for each type of item as a proportion of all responses of that type. Inspection of the means indicates that the frequency task was more difficult than the recency task for children in all the age groups. 
If subjects were relying on trace-strength, for once-presented items there should have been more erroneous " 3 times" responses to Day 2 items than to Day 1 items since Day 2 items would be more familiar. For repeated items, there should have been more erroneous "one time" responses to Day 1 items than Day 2 items since Day 1 items would be less familiar. In contrast, if frequency judgements were made by retrieving specific information about frequency of occurrence, then performance on Day 2 items would be expected to be better than performance on Day 1 items, since forgetting would lead to a loss of such information. As with recency judgements, reliance on tracestrength would lead to an interaction between the effect of recency and the effect of frequency of presentation, whereas use of specific frequency information would yield a consistent effect of recency of presentation only.

Although frequency judgements were less accurate than recency judgements, the proportions of responses which were erroneous were low. Accuracy appears to improve with age, and fewer erroneous responses seem to have been made to Day 2 items. A four-way analysis of variance (ANOVA) was carried out on the error proportions, with between-subjects factors of Age and Order of test and within-subjects factors of Day and Frequency. There was a significant effect of Age $[F(2,48)=5.49, p<.01]$, which a NewmanKeuls pairwise comparison showed to be due to the performance of the 4year-olds being significantly worse $(p<.01)$ than that of the other two groups. There was no significant difference between the two older groups. The main effect of Order was not significant $[F(1,48)=1.0, p=.32]$. The effect of Day was significant $[F(1,48)=19.40, p<.01]$, with performance on Day 2 items being better than that on Day 1 items.

If frequency judgements are mediated by an assessment of trace-strength, then an interaction is expected between frequency and recency of presentation since more erroneous responses would be given to more familiar Day 2 items when items were shown only once, but more erroneous responses would be given to less familiar Day 1 items when items were repeated. The interaction between Day and Frequency was significant $[F(1,48)=6.74, p<.05]$. Simple effects analysis revealed that there was an effect of Day at Frequency 3 only $[F(1,48)=20.23, p<.01]$, and an effect of Frequency at Day 2 only $[F(1,48)$ $=8.32, p<.01]$. A Newman-Keuls pairwise comparison revealed that significantly fewer errors were made on Day 2 Frequency 3 items $(p<.05)$ than on any other items. Thus, more Frequency 1 judgements were made to Day 1 Frequency 3 items than Day 2 Frequency 3 items. However, the number of Frequency 3 judgements made to Day 1 Frequency 1 items was no different from that of Day 2 Frequency 1 items, so the nature of the interaction is different from the one predicted if children were relying on trace-strength. In fact, both kinds of Day 2 items were assessed for frequency more accurately than Day 1 items, as predicted if subjects were using information specifically about frequency.

Children's memory for whether or not an item reoccurred was, therefore, 
4-year-olds

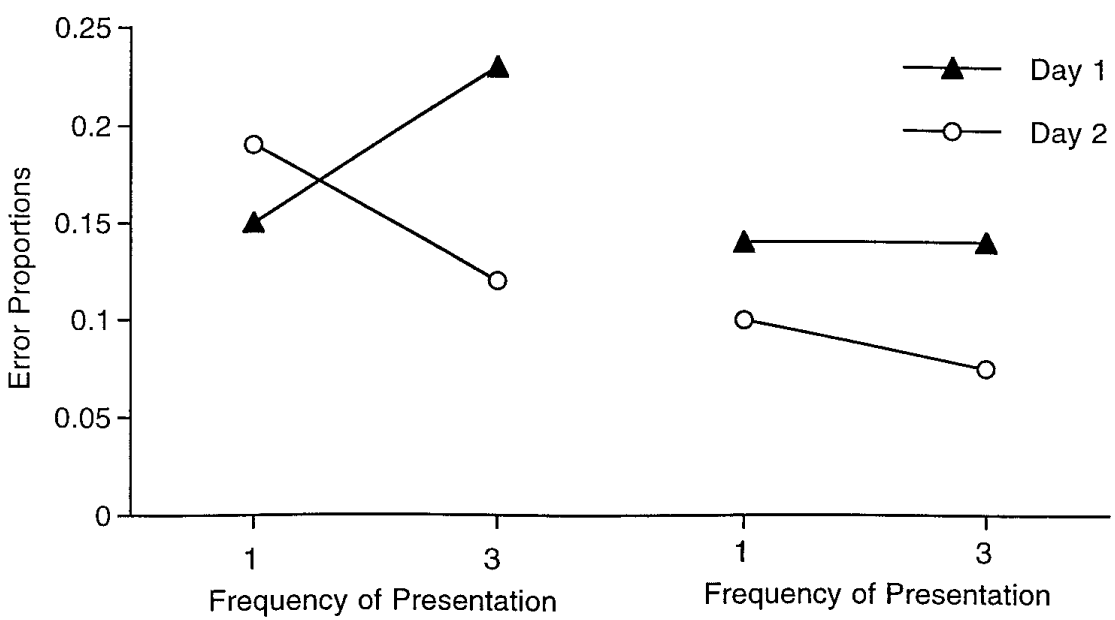

FIG. 2. Mean proportions of frequency responses that are errors for 4-year-olds and for 6and 8-year-olds combined.

more accurate when presentation was recent. The good performance on Day 2 Frequency 3 items, which underlies the interaction found between frequency and recency, may be due to the ease of remembering reoccurrence when presentation is more recent, compared to judging that an item did not reoccur. Judging that an item did not reoccur might be more difficult since it may involve a more comprehensive memory search; therefore, performance on Day 2 Frequency 3 items would be expected to be better than Day 2 Frequency 1 items.

However, inspection of Fig. 2 reveals that the overall pattern of performance of the 4-year-olds differed from that of the two older groups. The older children were better on both kinds of Day 2 items than on Day 1 items. The younger children differed in that they were poorer on Day 2 Frequency 1 items than Day 1 Frequency 1, which suggests that, in fact, the younger children were indeed reliant on trace-strength, as hypothesised. In Fig. 2, the performance of the 4-year-olds can be contrasted with that of the older children who showed a consistent benefit for recent items. The interaction between Age, Day, and Frequency did approach significance $[F(2,48)=2.39, p=.10]$.

Post-hoc analysis of the 4-year-olds' performance showed that their pattern of errors differed from the pattern of the 6- and 8-year-olds. Although there was no significant main effect of Day $[F(1,17)=2.1, p=.17]$, the interaction between Day and Frequency was significant $[F(1,17)=9.27, p<.01]$. Analysis of simple effects showed that there was a significant effect of Frequency on both Day $1[F(1,17)=4.5, p<.05]$ and Day $2[F(1,17)=5.23, p<.05)$, 
whereas in the older groups there had been a significant effect of Frequency on Day 2 only. This effect differed in direction over the 2 days: on Day 1, judgements were more accurate for items seen one time, whereas on Day 2 judgements were more accurate for items seen three times. However, as with the older children, there was a significant effect of Day on Frequency 1 items only $[F(1,17)=7.96, p<.05]$ whereas the effect of Day on Frequency 3 responses failed to reach significance $[F(1,17)=2.24, p=.15]$, although the directions of all effects were as predicted by a trace-strength account.

To summarize, there is a developmental improvement in the ability to make frequency judgements, although, as with recency judgements, there were no differences between the two older groups. On the whole, children found it easier to make frequency judgements for items which had been presented more recently, particularly when items had been repeated. There was a trend which suggested that the younger children may, in fact, be more reliant on trace-strength in making such judgements.

\section{DISCUSSION}

Although even the youngest children performed well above chance on the recency task, the results of this study provide evidence of developmental improvement between 4 and 6 years of age in the ability to make recency judgements. However, the findings do not support the idea that there is a developmental shift from reliance on trace-strength to episodic or contextual retrieval. Children from all age-groups also performed well above chance on the frequency task with a similar developmental improvement between 4 and 6 years. The 4-year-olds' pattern of performance on this task was similar to that predicted if they were relying on trace-strength, although this trend did not reach significance.

Brown (1973b) has argued that developmental differences will only emerge on recency tasks in which mnemonic strategies can be employed, since simple recency tasks involve the retrieval of automatically stored temporal codes (Hasher \& Zacks, 1979). Indeed, the results of some previous studies had indicated that the development of strategies (Brown, 1973a, 1973b; Brown et al., 1974) or knowledge of temporal patterns (Friedman, 1991) is responsible for developmental improvement in temporal tasks. However, the nature of the current task is such that it would seem difficult to explain the developmental improvement in terms of the emergence of a mnemonic strategy such as rehearsal, since the lists were much too long to be rehearsed and encoding of temporally relevant information was incidental (although general memory instructions had been given). Since knowledge of long-term time patterns is not relevant to the task either, it seems that developmental changes in other memory processes need to be considered.

There was, however, no support for the hypothesis that the fundamental change is a shift from reliance on trace-strength information to retrieval of episodic information. Young children do not show the pattern of errors which 
would result if they confounded recency and frequency of presentation. Instead, under most circumstances, it was the case that presenting items more than once enabled more accurate judgements. Repetition of an item seemed to increase the contextual information available for that item, leading to a better basis for temporal judgements. Thus, it is likely that children in all age-groups were using some kind of contextual information as a basis for their judgements. However, one anomalous finding was the lack of an advantage of repetition of Day 2 items in the 4-year-old group, which remains unexplained.

The failure to find a developmental shift from reliance on trace-strength may add support to Friedman's (1993) model of temporal memory, in which this basis is conceptualized as a backup strategy. He has suggested that young children are, in principle, able to use contextual information to make recency judgements (Friedman, 1992a) but lack the necessary grasp of long-term temporal patterns when judgements involve temporally distant events. Therefore, they rely on trace-strength in making recency judgements for some reallife events. However, in the present task, in which grasp of such temporal patterns is unnecessary, young children will not be forced to rely on impressionistic comparisons.

The developmental improvement between 4 and 6 years of age found in the present task must be explained in terms of quantitative improvements in the encoding, retrieval, or use of the kind of temporally relevant information that forms the basis of recency judgements. Such a position is contrary to Hasher and Zacks' (1979) suggestion that simple recency judgements involve automatic processes which will not show age-related changes. Thus, either recency judgements on this kind of task do not involve automatic processes by their criteria or the processes become automatic between 4 and 6 years of age. Since no difference was found between the two older groups, it is not possible to decide between these two possibilities.

The second finding of this study was a developmental improvement between 4 and 6 years of age in the ability to make frequency judgements. It has been argued that the ability to make frequency judgements is based on specific information about frequency which is encoded automatically (Hasher \& Zacks, 1979; Hasher \& Zacks, 1984) and that this process does not show developmental change. The results of this study, however, indicate that the ability to make frequency judgements does improve between 4 and 6 years of age, although not between 6 and 8 .

The pattern of errors in the youngest group on the frequency task was suggestive of a reliance on trace-strength, although the developmental trend failed to reach significance. Given this suggestive result, the mixed findings of developmental improvement and invariance in frequency tasks might be explicable in terms of a shift from reliance on trace-strength. If using tracestrength as a basis for frequency judgements yields fairly accurate responding due to the nature of the task, then young children may do as well as older children, although the basis of their judgements may differ. However, in some 
tasks, accurate responding requires retrieval of specific information about frequency, in which case developmental improvements will be found. Deciding to carry out a memory search for specific information about frequency, as opposed to basing frequency judgements on trace-strength information, may be a developing ability, which requires experience of how to make such judgements accurately and certain memory skills. However, this is speculative since there is only moderate evidence for young children's reliance on familiarity in the frequency task.

In summary, although this study establishes that there are developmental improvements in recency judgements, and rules out a simple explanation in terms of a shift from reliance on trace-strength, it raises the question of the exact nature of developmental changes. One possibility is that memory for temporally relevant contextual information is generally poor in young children. The fact that even young children were not relying on familiarity in the recency task and are performing well above chance would suggest that they are actually capable of encoding, retrieving, and using some kind of contextual information, although the nature of developmental changes in the retrieval and use of such information has not been established. Lastly, there was developmental improvement in frequency judgements between 4 and 6 years of age and suggestive evidence that this was due to a shift from reliance on familiarity.

\section{REFERENCES}

Bartlett, J. C., Strater, L., \& Fulton, A. (1991). False recency and false fame of faces in young adulthood and old age. Memory \& Cognition, 19, 177-198.

Block, R. A. (1982). Temporal judgements and contextual change. Journal of Experimental Psychology: Learning, Memory and Cognition, 8, 530-544.

Brown, A. L. (1973a). Mnemonic elaboration and recency judgements in children. Cognitive Psychology, 5, 223-248.

Brown, A. L. (1973b). Judgements of recency for long sequences of pictures: The absence of a developmental trend. Journal of Experimental Child Psychology, 15, 473-480.

Brown, A. L., Campione, J. C., \& Gilliard, D. M. (1974). Recency judgements in children: A production deficiency in the use of redundant background cues. Developmental Psychology, 10, 303.

Cermack, L. S., Verfaellie, M., \& Sweeney, M. (1992). Fluency versus conscious recollection in the word completion performance on amnesic patients. Brain and Cognition, 20, $367-$ 377.

Connolly, D. A., Hockley, W. E., \& Pratt, M. W. (1996). Developmental evaluation of frequency memory for actions represented in lists, scripts and stories. Memory, 4, 243-263.

Ellis, N. R., Palmer, R. L., \& Reeves, C. L. (1988). Developmental and intellectual differences in frequency processing. Developmental Psychology, 24, 38-45.

Friedman, W. J. (1978). Development of time concepts in children. In H. W. Reese \& L. P. Lipsitt (Eds.), Advances in child development and behaviour (pp. 267-298). New York: Academic Press.

Friedman, W. J. (1986). The development of children's knowledge of temporal structure. Child Development, 57, 1386-1400.

Friedman, W. J. (1989). The representation of temporal structure in children, adolescents and 
adults. In I. Levin \& D. Zakay (Eds.), Time and human cognition: A life-span perspective (pp. 259-305). Amsterdam: North-Holland/Elsevier.

Friedman, W. J. (1991). The development of children's memory for the time of past events. Child Development, 62, 139-155.

Friedman, W. J. (1992a). Time memory and time perception. In F. Macar \& J. Jackson (Eds.), Time, action and cognition (pp. 165-172). Amsterdam: Kluwer.

Friedman, W. J. (1992b). Children's time memory: The development of a differentiated past. Cognitive Development, 7, 171-187.

Friedman, W. J. (1993). Memory for the time of past events. Psychological Bulletin, 113, 4466.

Friedman, W. J., Gardner, A. G., \& Zubin, N. R. E. (1995). Children's comparison of the recency of two events from the past year. Child Development, 66, 970-983.

Friedman, W. J., \& Wilkins, A. J. (1985). Scale effects in memory for the time of events. Memory \& Cognition, 13, 168-175.

Ghatala, E. S., \& Levin, J. L. (1973). Developmental differences in frequency judgements of words and pictures. Journal of Experimental Child Psychology, 16, 495-507.

Guenther, R. K., \& Linton, M. (1975). Mechanisms of temporal coding. Journal of Experimental Psychology: Learning, Memory and Cognition, 12, 3-15.

Harner, L. (1975). Yesterday and tomorrow: Development of early understanding of the terms. Developmental Psychology, 11, 864-865.

Hasher, L., \& Zachs, R. T. (1979). Automatic and effortful processes in memory. Journal of Experimental Psychology: General, 108, 356-388.

Hasher, L., \& Zacks, R. T. (1984). Automatic processing of fundamental information: The case of frequency of occurrence. American Psychologist, 39, 1372-1388.

Hinrichs, J. V. (1970). A two-process memory-strength theory for judgements of recency. Psychological Review, 77, 223-233.

Hintzman, D. L., Block, R., \& Summers, J. (1973). Contextual associations and memory for serial position. Journal of Experimental Psychology, 97, 220-229.

Huppert, F. A., \& Piercy, M. (1978). The role of trace strength in recency and frequency judgements by amnesic and control subjects. The Quarterly Journal of Experimental Psychology, 30, 346-354.

Jacoby, L. L. (1991). A process dissociation framework: Separating automatic from intentional uses of memory. Journal of Memory and Language, 30, 513-541.

Lund, A. M., Hall, J. W., Wilson, K. P., \& Humphreys, M. S. (1983). Frequency judgment accuracy as a function of age and school achievement (learning disabled versus non-learning disabled) patterns. Journal of Experimental Child Psychology, 35, 236-247.

McCormack, T., \& Russell, J. (1995). Developmental change in recognition memory and temporal discrimination. Poster presented at the Biennial Meeting of the Society for Research in Child Development, Indianapolis, IN.

Mayes, A. R., Baddeley, A. D., Cockburn, J., Meudell, P. R., Pickering, A., \& Wilson, B. (1989). Why are amnesic judgements of recency and frequency made in a qualitatively different way from those of normal people? Cortex, 25, 479-488.

Mayes, A. R., Meudell, P. R., \& Pickering, A. (1985). Is organic amnesia caused by a selective deficit in remembering contextual information? Cortex, 21, 167-202.

Meudell, P. R., Mayes, A. R., Ostergaard, A., \& Pickering, A. (1985). Recency and frequency judgments in alcoholic amnesics and normal people with poor memory. Cortex, 21, 487511.

Naito, M., \& Komatsu, S. (1993). Processes involved in childhood development of implicit memory. In P. Graf \& M. E. J. Masson (Eds.), Implicit memory: New directions in cognition, development and neuropsychology (pp. 231-259). Hillsdale, NJ: Erlbaum.

Parkin, A. J., Leng, N. R. C., \& Hunkin, N. M. (1990). Differential sensitivity to context in diencephalic and temporal lobe amnesia. Cortex, 26, 373-380. 
Parkin, A., \& Streete, S. (1988). Implicit and explicit memory in young children and adults. British Journal of Psychology, 79, 362-369.

Parkin, A. J., \& Walter, B. M. (1992). Recollective experience, normal aging and frontal dysfunction. Psychology and Aging, 7, 290-298.

Roediger, H. L. (1990). Implicit memory: A commentary. Bulletin of the Psychonomic Society, 28, 378-380.

Rybash, J. M., \& Colilla, J. L. (1994). Source memory deficits and frontal lobe functioning in children. Developmental Neuropsychology, 10, 67-73.

Schacter, D. L. (1987). Implicit memory: History and current status. Journal of Experimental Psychology; Learning, Memory and Cognition, 13, 501-518.

Schacter, D., \& Moscovitch, M. (1984). Infants, amnesics and dissociable memory systems. In M. Moscovitch (Ed.), Infant memory (pp. 173-210). New York: Plenum.

Shaw, C., \& Aggleton, J. P. (1995). Evidence for the independence of recognition and recency memory in amnesic subjects. Cortex, 31, 57-71.

Shimamura, A. P., Janowsky, J. S., \& Squire, L. R. (1991). What is the role of frontal lobe damage in memory disorders? In M. S. Levin, H. M. Eisenberg, \& A. L. Benton (Eds.), Frontal lobe function and dysfunction (pp. 173-195). Oxford: Oxford Univ. Press.

Squire, L. R. (1982). Comparisons between forms of amnesia: Some deficits are unique to Korsakoff's syndrome. Journal of Experimental Psychology: Learning, Memory and Cognition, 8, 560-571.

Tulving, E. (1983). Elements of episodic memory. Oxford: Oxford Univ. Press.

Tulving, E. (1985). How many memory systems are there ? American Psychologist, 4, 385-398

Tzeng, O. J. L., Lee, A. T., \& Wetzel, C. D. (1979). Temporal coding in verbal information processing. Journal of Experimental Psychology: Human Learning and Memory, 5, 52-64.

Verfaellie, M., Bauer, R. M., \& Bowers, D. (1991). Autonomic and behavioral evidence of implicit memory in amnesia. Brain and Cognition, 15, 10-25.

Verfaellie, M., \& Treadwell, J. R. (1993). Status of recognition memory in amnesia. Neuropsychology, 1, 5-13.

Wickelgren, W. A., \& Norman, D. A. (1966). Strength models and serial position in short-term recognition memory. Journal of Mathematical Psychology, 6, 316-347.

ReCEIVED: October 17, 1996; REVISED: April 11, 1997 